\title{
Inhibition of Recombining Binding Protein Suppressor of Hairless (RBPJ) Impairs the Growth of Prostate Cancer
}

\author{
Li Xue Hecheng Li Qi Chen Zhenlong Wang Peng Zhang Haiwen Chen \\ Ziming Wang Tie Chong
}

Department of Urology, Second Affiliated Hospital, School of Medicine, Xi'an Jiaotong University, Xi'an, China

\section{Key Words}

RBPJ • Cancer growth $•$ Prostate cancer $•$ Notch signaling pathway

\begin{abstract}
:
Background/Aims: Notch signaling pathway regulates cancer cell growth. RBPJ is a key transcription factor downstream of Notch receptor activation, whereas the role of RBPJ in carcinogenesis of prostate cancer is ill-defined. Methods: Here, we evaluated the effects of RBPJ inhibition on the growth of prostate cancer cells. We knocked down RBPJ in prostate cancer cells by a short hairpin interfering RNA (shRNA). We measured cell growth by an MTT assay. We analyzed the levels of cell-cycle-associated proteins by Western blot. Results: We found that shRNA for RBPJ efficiently inhibited RBPJ expression in prostate cancer cells, resulting in a significant decrease in the cell growth. Further, RBPJ-mediated cell-growth inhibition appeared to be resulting from alteration of cell-cycle inhibitors p21 and p27, cellcycle activators CDK2, CDK4 and CyclinD1, and apoptosis-suppressor Bcl-2. Conclusion: Our data suggest that shRNA intervention of RBPJ expression could be a promising therapeutic approach for treating human prostate cancer.
\end{abstract}

Copyright $@ 2015$ S. Karger AG, Basel

\section{Introduction}

Prostate cancer is one of the most common cancers in aged men [1-4]. Although our understanding and treatment of prostate cancer have significantly improved in the past years, the molecular regulation of the growth of prostate cancer cells is not yet clarified [1-9].

The Notch pathway has been shown to upregulate in many types of cancer, which suggests a role of this pathway in the tumorigenesis. Notch signaling pathway is highly 
conserved in evolution and plays important roles during development, in which Notch signals regulate various physiological processes, including maintenance of stem cells, cell fate decisions, proliferation, differentiation and apoptosis $[10,11]$.

Recombination signal-binding protein J $(\mathrm{RBPJ})$ is a DNA-binding protein from CSL family of transcription factors [12]. RBPJ recognizes a consensus sequence C(T)GTGGGAA on RBPJ-binding sites from a number of factors [12]. Importantly, RBPJ also mediates signals from Notch receptors [13-15]. In the absence of Notch signals, RBPJ is associated with some corepressors that repress Notch transcription. After ligand binding, Notch signaling is initiated by $\gamma$-secretase-mediated proteolytic cleavage and liberation of the Notch intracellular domain (NICD). NICD subsequently translocates into the nucleus to displace corepressors from RBPJ, which allows for the recruitment of coactivators to bind with RBPJ to thereby induce the activation of target genes like hairy and enhancer of split 1 (Hes-1), cyclin-dependent kinase 2 (CDK2), B-cell CLL/lymphoma 2 (Bcl-2), ubiquitin ligase complex SCFSKP2 (SKP2), p21 and p27 [13, 14, 16-21].

Although RBPJ has been shown to play a role in the tumorigenesis of some cancers, and inhibition of RBPJ significantly may impair or promote cancer growth depending on cancer cell type, the knockdown of RBPJ by RNA interference (RNAi) in prostate cancer cells has not been studies.

Here, we evaluated the regulation of prostate cancer cells by RBPJ depletion. We used a short hairpin RNA (shRNA) to efficiently inhibit RBPJ expression in prostate cancer cells, which significantly decreased the cancer cell growth. Further analyses showed that RBPJ inhibition altered the levels of its downstream targets, including p21, p27, CDK2, CDK4, CyclcinD1 and Bcl-2, to suppress the growth of the prostate cancer cells.

\section{Materials and Methods}

Cell culture

HEK293T cells and human prostate cancer cell lines PC3 and DU145 were purchased from ATCC (American Type Culture Collection, Manassas, VA, USA), and have been described before [22, 23]. These two cell lines were all cultured in in Dulbecco's modified Eagle's medium (DMEM, Invitrogen, Carlsbad, CA, USA) supplemented with $10 \%$ fetal bovine serum (Invitrogen) and $1 \%$ penicillin and streptomycin in a $5 \% \mathrm{CO}_{2}$ humidified cell-culture incubator at $37^{\circ} \mathrm{C}$.

\section{RT-qPCR}

Total RNA was extracted from cultured cells with RNeasy kit (Qiagen, Hilden, Germany). cDNA was synthesized from $1 \mu \mathrm{g}$ of total RNA using a reverse transcription kit (Qiagen) and purified with the QIAquick PCR Purification Kit (Qiagen). Quantitative PCR (RT-qPCR) was performed in duplicates with QuantiTect SYBR Green PCR Kit (Qiagen) with a LightCycler 1.5 Real-time PCR machine (Roche, Indianapolis, IN, USA). Primers were designed to amplify the fragments cross exons are: RBPJ (132 bp), forward primer 5'-CGCATTATTGGATGCAGATG-3' and reverse primer 5'-CAGGAAGCGCCATCATTTAT-3'; $\alpha$-tubulin (125 bp), forward primer 5'-CCAAGCTGGAGTTCTCTA-3', reverse primer 5'-CAGAGTGCTCCAGG-3'. Values of RBPJ were first normalized against GAPDH and then compared with controls.

\section{Preparation of RBPJ-shRNAs}

The coding sequence of RBPJ was amplified with forward primer 5'-GGAAGATGGCGCCTGTTGTGACAG-3' and reverse primer 5'-GTTATCTCGAGTCAAGCGTAGTCTGGGACGGTATGGGTAGGACACCACGGTTGCTGTG-3'. The underlined sequence represents a HA tag. The amplicons were digested with Xhol and BamHI and subcloned into a pcDNA3.1 expression vector (Invitrogen), resulting in a construct named pcDNA-RBPJ. Short hairpin interfering RNAs (shRNAs) targeting RBPJ mRNA (NM_005349.3) were designed, according to the Dharmacon siDESIGN Center database. Five shRNAs that target the RBPJ coding region were selected based on ranking criteria of Reynolds [24]. All the shRNAs were cloned into pLKO.1 vector (Sigma-Aldrich, St. Louis, MO, USA), with pLKO.1 itself (with a scrambled shRNA) used as control.

\section{KARGER}




\section{Cellular Physiology Cell Physiol Biochem 2015;36:1982-1990 \begin{tabular}{l|l} 
and Biochemistry Published onIIne: July 17, 2015 & $\begin{array}{l}\text { C 2015 S. Karger AG, Basel } \\
\text { www.karger.com/cpb }\end{array}$ \\
\hline
\end{tabular} \\ Xue et al.: RBPJ in Prostate Cancer}

Transfection

HEK293T cells were seeded in six-well plates in complete media one day prior to transfection. To generate the recombinant, the HEK293T packaging cells were transfected with 5-8 $\mu \mathrm{g}$ pVSV-G (Clontech, Mountain View, CA) and $15 \mu \mathrm{g}$ of recombinant vectors using Lipofectamine-2000 (Invitrogen), according to the manufacturer's instruction. The transfected cells were then harvested and whole cell lysates were extracted for Western blot using an anti-RBPJ antibody (Abcam, Cambridge, MA, USA).

Generation of RBPJ knockdown stable clones of prostate cancer cells

To generate RBPJ-shRNA lentiviral particles, HEK293T cells were seeded in a $100 \mathrm{~mm}$ dish at 50,000 cells $/ \mathrm{cm}^{2}$ and co-transfected with $10 \mu \mathrm{g}$ of RBPJ-shRNA and $5 \mu \mathrm{g}$ each of packaging plasmids (REV, pMDL and VSV-G) using Lipofectamine-2000 (Invitrogen). The supernatant containing lentiviral particles was collected 48 hours after transfection and filtered through a $0.45 \mu \mathrm{m}$ syringe filter. Target prostate cancer cells were seeded in $100 \mathrm{~mm}$ plates at 15,000 cells $/ \mathrm{cm}^{2}$ one day prior to lentiviral infection. The lentiviral particles were added along with $10 \mu \mathrm{g} / \mathrm{ml}$ polybrene (Sigma-Aldrich) to the cell culture for 24 hours. Then the cells were washed twice with complete media and cultured in the presence of puromycin to select the transduced cells.

Western blot analyses

Proteins were extracted in a solution of RIPA and Protease Inhibitor Cocktail (Thermo Scientific, Waltham, MA, USA) from HEK293T cells or prostate cancer cells and subjected to SDS-PAGE. Quantification of total protein was carried out using BCA kit (Sigma-Aldrich). The proteins $(100 \mu \mathrm{g})$ were subjected to $12 \%$ SDS-PAGE. Separated proteins were electrophoretically transferred to a nitrocellulose membrane (BioRad, Hercules, CA, USA) and immune-blotted with monoclonal mouse anti-human RBPJ (Abcam), polyclonal rabbit anti-human p21 (Abcam), polyclonal rabbit anti-human p27 (Abcam), polyclonal rabbit anti-human Hes1 (Abcam), polyclonal rabbit anti-human SKP2 (Cell Signaling, San Jose, CA, USA) or polyclonal rabbit anti-human $\alpha$-tubulin (Cell Signaling) antibodies. GAPDH was used as a protein loading control. Secondary antibody is HRP-conjugated anti-rabbit (Jackson Labs, Bar Harbor, ME, USA). Images shown in the figure were representative from 5 repeats. Densitometry of Western blots was quantified with NIH ImageJ software.

Cell growth assay

A diphenyltetrazolium bromide (MTT) assay was performed to determine cell growth. Five thousand cells per well were seeded in a 96-well plate and grown for 24, 48 and 72 hours. Then the media were removed and washed with PBS, after which 5g/l of thiazolyl tetrazolium (Amersco, Indianapolis, IN, USA) was added to each well. Four hours later, MTT was removed and $150 \mu \mathrm{l}$ of dimethyl sulfoxide (Sigma-Aldrich, St. Louis, MO, USA) was added. The viability of the cells was calculated from the absorption at $570 / 630 \mathrm{~nm}$ with an enzyme-linked immunosorbent assay reader.

Cell cycle analyses

Cell pellets were resuspended in a cold solution containing $100 \mu \mathrm{g} / \mathrm{ml}$ propidium iodide (SigmaAldrich), $0.1 \%$ Tri-sodium citrate, and $10 \%$ RNaseA $(1 \mathrm{mg} / \mathrm{ml})$ and then incubated at $37^{\circ} \mathrm{C}$ for $30 \mathrm{~min}$. Cell cycles were then analyzed by flow cytometry.

\section{Statistics}

All statistical analyses were carried out using the SPSS 19.0 statistical software package. All data were statistically analyzed using one-way ANOVA with a Bonferoni Correction. All values are depicted as mean \pm standard deviation from 5 individuals and are considered significant if $\mathrm{p}<0.05$.

\section{Results}

RBPJ expression was effectively inhibited by shRNA constructs

Multiple shRNA constructs were generated and then co-transfected with pcDNA-RBPJ into HEK293T cells to determine their potentials of silencing RBPJ expression. RBPJ protein levels in the transfected cells were determined by Western blot. All 4 shRNAs resulted in 
Fig. 1. Selection of shRNAs that inhibit RBPJ expression. (A-B) Western blot for RBPJ in HEK293T cells transfected with pcDNA-RBPJ plasmids, shown by representative images (A), and by quantification (B). Scr, cells transfected with pLKO.1 vector with a scrambled shRNA. shRBPJ-a to shRBPJ-d, different shRNA constructs designed to target RBPJ based on mRNA sequence. GAPDH was a protein loading control. ${ }^{*} \mathrm{p}<0.05 . \mathrm{n}=5$. Statistics: one-way ANOVA with a Bonferoni Correction.
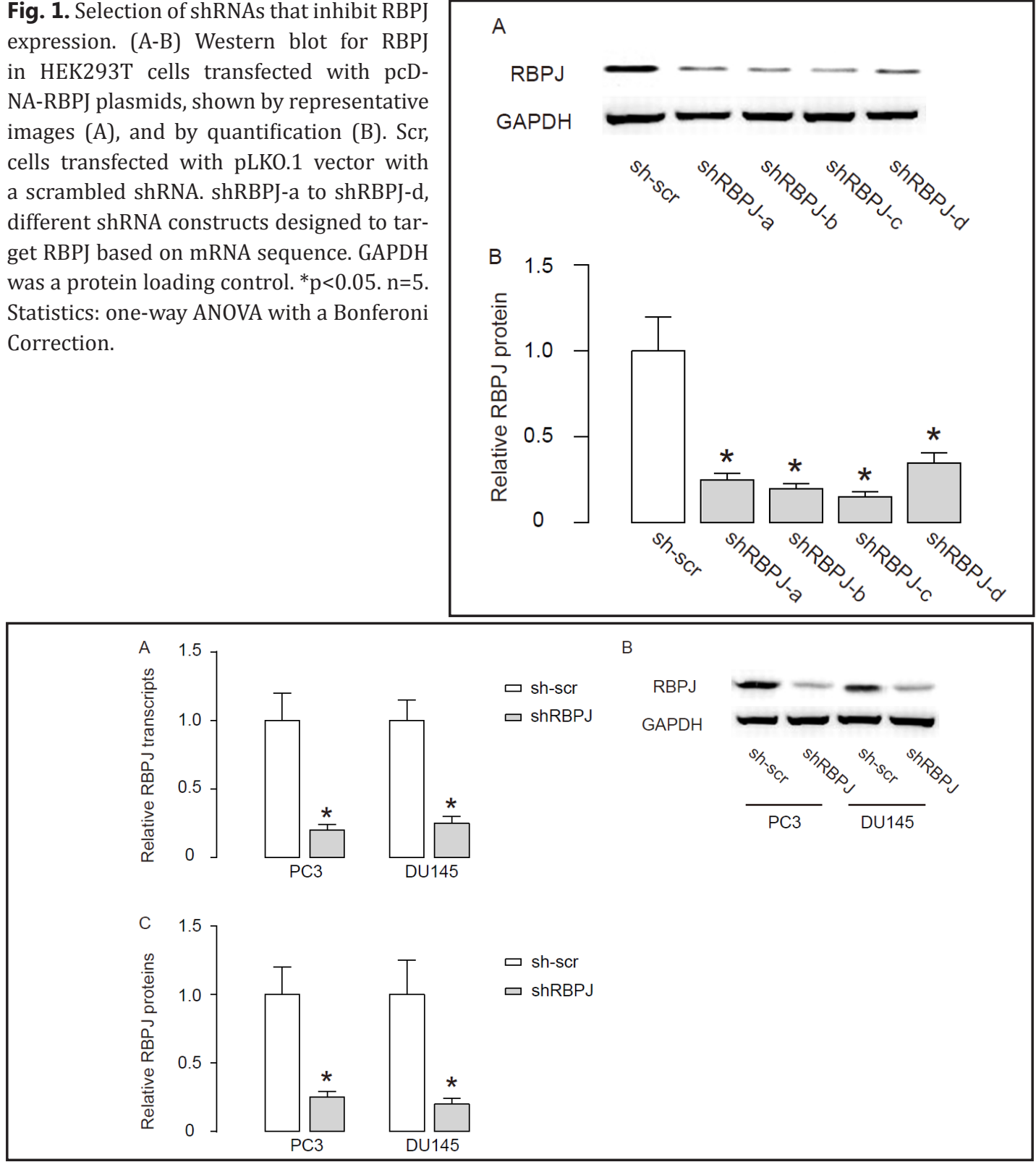

Fig. 2. Inhibition of RBPJ by lenti-shRBPJ-c in stably transduced prostate cancer cells. (A-C) Two prostate cancer cells were infected with RBPJ-shRNA and scr-carrying lentivirus to generate stable clones which were then cultured in media for 72 hours before they were harvested. RBPJ levels were significantly reduced in either stably transduced prostate cancer cell lines, by RT-qPCR (A), and by Western blot shown with representative images (B) and with quantification (C). GAPDH was a protein loading control. * $\mathrm{p}<0.05$. $n=5$. Statistics: one-way ANOVA with a Bonferoni Correction.

significant inhibition of RBPJ expression, among which shRBPJ-c was the most efficient one and reduced RBPJ levels in HEK293T cells by more than 85\% (Fig. 1A-B). Thus, shRBPJ-c was chosen to be used in the current study to knock down RBPJ expression in prostate cancer cells.

Inhibition of RBPJ by lenti-shRBPJ-c in stably transduced prostate cancer cells

Two human prostate cancer cell lines PC3 and DU145 were used in the current study, since they represent different types of prostate cancer. These prostate cancer cells were 

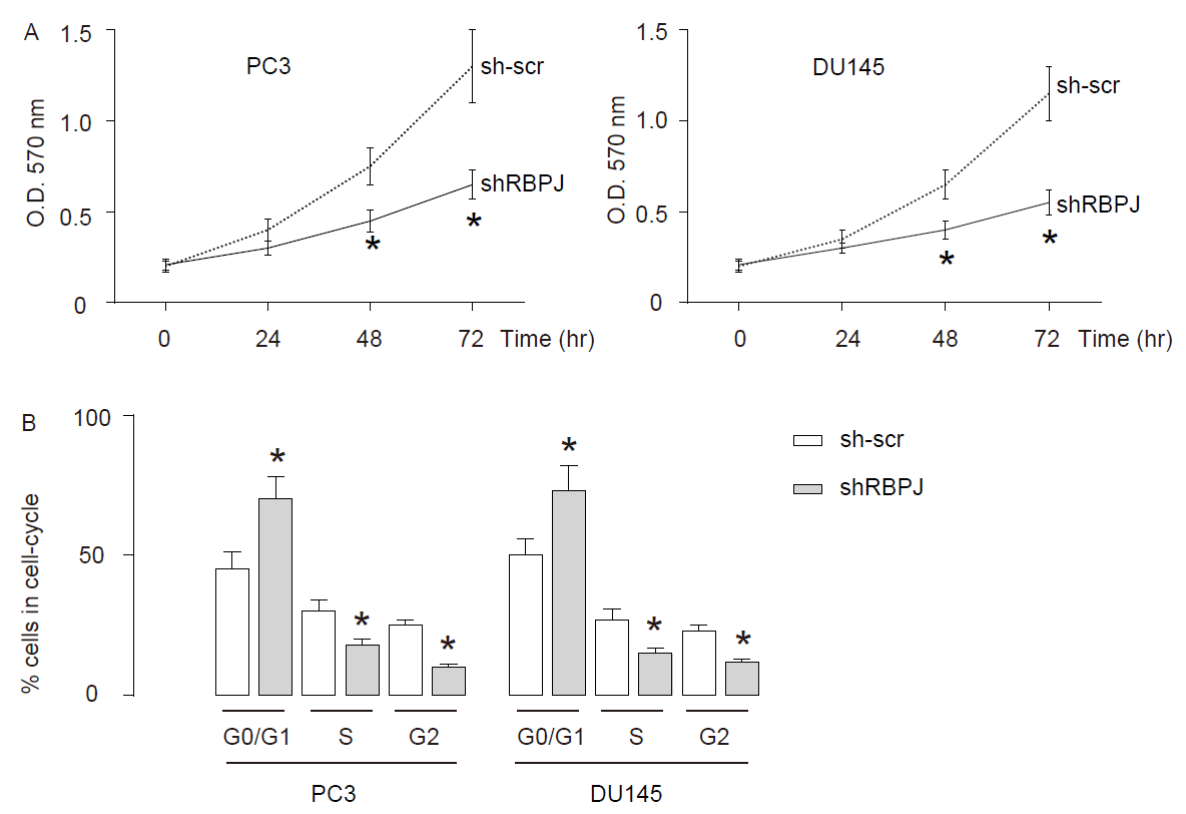

Fig. 3. Inhibition of RBPJ suppressed growth of prostate cancer cells. (A) Cell growth was examined in a MTT assay. Significant reduced cell growth by RBPJ inhibition was detected as early as 48 hours after seeding, compared with controls, in both lines. (B) Cancer cells were analyzed in a cell cycle phase assay at 72 hours after seeding, showing that the percentage of S-phase proliferating cells and G2-phase post-replicating cells in RBPJ-depleted prostate cancer cells significantly reduced, while the percentage of G0/G1-phase cells in RBPJ-depleted prostate cancer cells significantly increased, compared to mock cells. ${ }^{*} \mathrm{p}<0.05$. $n=5$. Statistics: one-way ANOVA with a Bonferoni Correction.

infected with RBPJ-shRNA and pLKO.1 lentivirus carrying scrambled sequence (scr) to generate stable clones which were then cultured in media for 72 hours before they were harvested. We found that RBPJ levels were significantly reduced in either stably transduced prostate cancer cell lines, by RT-qPCR (Fig. 2A), and by Western blot shown with representative images (Fig. 2B) and with quantification (Fig. 2C). These data suggest that shRBPJ inhibited $\mathrm{RBPJ}$ transcription, and reduced the RBPJ protein production in prostate cancer cells.

\section{Inhibition of RBPJ suppressed growth of prostate cancer cells}

In order to figure out whether inhibition of RBPJ may affect the growth of prostate cancer cells, we analyzed cell growth in a MTT assay. Significant reduced cell growth by RBPJ inhibition was detected as early as 48 hours after seeding, compared with controls, in both lines (Fig. 3A). We then analyzed these cancer cells in a cell cycle phase assay at 72 hours after seeding, and we found that the percentage of S-phase proliferating cells in RBPJdepleted prostate cancer cells significantly decreased, while the percentage of G0/G1-phase cells in RBPJ-depleted prostate cancer cells significantly increased, compared to the control scr-transfected cells (Fig. 3B). These results suggest that inhibition of RBPJ suppressed growth of prostate cancer cells, possibly through inhibiting cell proliferation.

\section{RBPJ-depletion inhibited cell proliferation by suppressing S-phase transition}

To understand the mechanism underlying the reduced cell growth by RBP depletion, we examined the expression of downstream targets of RBPJ by Western blot. CDK2 and CDK4 are catalytic subunits of the cyclin-dependent kinase complex, and their activities are restricted to the G1-S phase of the cell cycle for inducing G1-S transition. CyclinD1 is a cellcycle activator to form complexes with CDK2 and CDK4 to induce G1-S transition. The cellcycle inhibitor p21 inhibits formation of cyclin-CDK2 complexes. The p27 directly inhibits 
Fig. 4. RBPJ-depletion inhibited cell proliferation by suppressing S-phase transition. The levels of downstream targets of RBPJ were examined by Western blot, showing that RBPJ-depleted prostate cancer cells exhibited a reduction in the levels of CDK2, CDK4 and CyclinD1, but an increase in the levels of p21, p27 and Bcl-2, compared to control cells. GAPDH was a protein loading control.

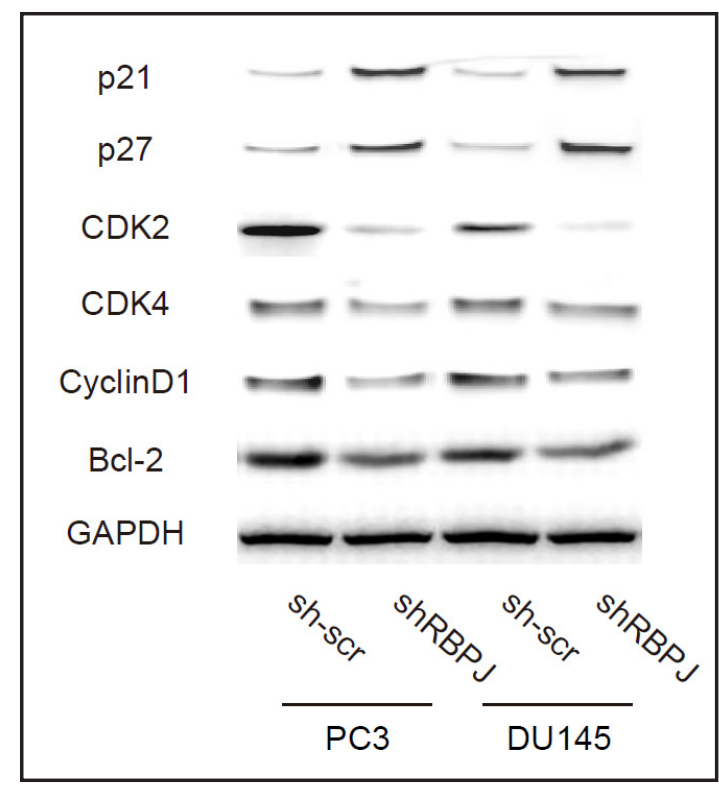

CDK4, resulting in cell arrest in the G1 phase of the cell cycle [13, 14, 16-21, 25-28]. We found that RBPJ-depleted prostate cancer cells exhibited a reduction in the levels of CDK2, CDK4, CyclinD1 and apoptosis-suppressor Bcl-2, but an increase in the levels of p21 and p27, compared to control cells (Fig. 4). These results further suggest that RBPJ-depletion inhibited cell proliferation by suppressing S-phase transition.

\section{Discussion}

Inhibition of Notch pathway has been shown to suppress tumorigenesis of prostate cancers [29-49]. Moreover, RBPJ acts downstream of the Notch pathway and has been shown to be essential for a functional activated Notch signaling [13, 14, 16-21]. Therefore, here we studied the specific role of RBPJ in the Notch pathway, and evaluated its effect as a potential therapeutic target for prostate cancer.

We used a lentivirus-mediated shRNA delivery method to stably suppress RBPJ gene expression. Both short interfering RNAs (siRNAs) and shRNAs are the most frequently applied methods to specifically and efficiently silence genes at the mRNA level [50,51]. Delivery of siRNAs or shRNAs by plasmid transfection to target cells suffers from low and variable transfection efficiency and only suppresses gene expression transiently $[50,51]$. On the contrary, lentiviral vectors are more efficient, and conduct stable gene delivery [50, 51]. The lentiviral vector pLKO.1 is able to integrate into the host genome that allows for the stable expression of shRNA.

Our results showed that the downregulation of RBPJ expression resulted in a significant reduction of cell growth in transduced prostate cancer cells, confirmed by cell cycle analyses showing that knockdown of RBPJ decreased S-phase proliferating cells. Moreover, we found that knockdown of RBPJ suppressed the expression of its target genes CDK2, CDK4, CyclinD1, and apoptosis-suppressor Bcl-2, but increased others like p21 and p27. The decreases in Bcl-2 may be feedback from alternation of CDKs and Cyclins. Given the roles of these genes in cell cycle progression, our results suggest that the knockdown of RBPJ inhibits prostate cancer cell proliferation by inducing cell-cycle arrest at G1 phase through inhibiting the G1-S transition, as well as by promoting cell apoptosis.

Since we examined two prostate cancer cell lines and got same results, our results should not be limited to an individual cell line. In another word, our results are unlikely to be cell-line specific. Since Notch signaling pathway has been shown to play essential roles in many cancers other than prostate cancer, here the inhibitory effect of RBPJ-depletion on 
growth of prostate cancer cells may also be not limited to an individual cancer type. Future studies may be designed to test this model in other cancers in humans.

\section{Disclosure Statement}

The authors have declared that no conflict of interest exists.

\section{Acknowledgement}

This study was supported by the Fundamental Research Funds for the Central Universities and the National Natural Science Foundation of China (NSFC 81200552 to L.X.)

\section{Reference}

1 Saylor PJ: Prostate cancer: The androgen receptor remains front and centre. Nat Rev Clin Oncol 2013;10:126-128.

2 Alva A, Hussain M: The changing natural history of metastatic prostate cancer. Cancer J 2013;19:19-24.

-3 Beltran H, Rubin MA: New strategies in prostate cancer: Translating genomics into the clinic. Clin Cancer Res 2013;19:517-523.

4 Xin L: Cells of origin for cancer: An updated view from prostate cancer. Oncogene 2013;32:3655-3663.

5 Huang S, Liao Q, Li L, Xin D: Pttg1 inhibits smad3 in prostate cancer cells to promote their proliferation. Tumour Biol 2014;35:6265-6270.

6 Xia Q, Li C, Bian P, Wang J, Dong S: Targeting smad3 for inhibiting prostate cancer metastasis. Tumour Biol 2014;35:8537-8541.

7 Lin R, Feng J, Dong S, Pan R, Zhuang H, Ding Z: Regulation of autophagy of prostate cancer cells by betacatenin signaling. Cell Physiol Biochem 2015;35:926-932.

-8 Li T, Zhao X, Mo Z, Huang W, Yan H, Ling Z, Ye Y: Formononetin promotes cell cycle arrest via downregulation of akt/cyclin d1/cdk4 in human prostate cancer cells. Cell Physiol Biochem 2014;34:13511358.

9 Gillies K, Wertman J, Charette N, Dupre DJ: Anterograde trafficking of cxcr4 and ccr2 receptors in a prostate cancer cell line. Cell Physiol Biochem 2013;32:74-85.

10 Hu YY, Zheng MH, Zhang R, Liang YM, Han H: Notch signaling pathway and cancer metastasis. Adv Exp Med Biol 2012;727:186-198.

11 Wang Z, Li Y, Banerjee S, Sarkar FH: Exploitation of the notch signaling pathway as a novel target for cancer therapy. Anticancer Res 2008;28:3621-3630.

12 Hsieh JJ, Hayward SD: Masking of the cbf1/rbpj kappa transcriptional repression domain by epstein-barr virus ebna2. Science 1995;268:560-563.

13 Castel D, Mourikis P, Bartels SJ, Brinkman AB, Tajbakhsh S, Stunnenberg HG: Dynamic binding of rbpj is determined by notch signaling status. Genes Dev 2013;27:1059-1071.

-14 Hori K, Cholewa-Waclaw J, Nakada Y, Glasgow SM, Masui T, Henke RM, Wildner H, Martarelli B, Beres TM, Epstein JA, Magnuson MA, Macdonald RJ, Birchmeier C, Johnson JE: A nonclassical bhlh rbpj transcription factor complex is required for specification of gabaergic neurons independent of notch signaling. Genes Dev 2008;22:166-178.

15 Shi C, Qian J, Ma M, Zhang Y, Han B: Notch 3 protein, not its gene polymorphism, is associated with the chemotherapy response and prognosis of advanced nsclc patients. Cell Physiol Biochem 2014;34:743-752.

16 Guo D, Ye J, Dai J, Li L, Chen F, Ma D, Ji C: Notch-1 regulates akt signaling pathway and the expression of cell cycle regulatory proteins cyclin d1, cdk2 and p21 in t-all cell lines. Leuk Res 2009;33:678-685.

17 Gao F, Yao M, Shi Y, Hao J, Ren Y, Liu Q, Wang X, Duan H: Notch pathway is involved in high glucose-induced apoptosis in podocytes via bcl-2 and p53 pathways. J Cell Biochem 2013;114:1029-1038. 


\section{Cellular Physiology Cell Physiol Biochem 2015;36:1982-1990 \begin{tabular}{l|l} 
and Biochemistry Published onIIne: July 17, 2015 & $\begin{array}{l}\text { C 2015 S. Karger AG, Basel } \\
\text { www.karger.com/cpb }\end{array}$ \\
\hline
\end{tabular} \\ Xue et al.: RBPJ in Prostate Cancer}

18 Jarriault S, Le Bail O, Hirsinger E, Pourquie O, Logeat F, Strong CF, Brou C, Seidah NG, Isra l A: Delta-1 activation of notch-1 signaling results in hes-1 transactivation. Mol Cell Biol 1998;18:7423-7431.

19 Dohda T, Maljukova A, Liu L, Heyman M, Grander D, Brodin D, Sangfelt O, Lendahl U: Notch signaling induces skp2 expression and promotes reduction of p27kip1 in t-cell acute lymphoblastic leukemia cell lines. Exp Cell Res 2007;313:3141-3152.

-20 Nakamura T, Miyagawa S, Katsu Y, Mizutani T, Sato T, Takeuchi T, Iguchi T, Ohta Y: P21 and notch signalings in the persistently altered vagina induced by neonatal diethylstilbestrol exposure in mice. J Vet Med Sci 2012;74:1589-1595.

21 Marcelo KL, Sills TM, Coskun S, Vasavada H, Sanglikar S, Goldie LC, Hirschi KK: Hemogenic endothelial cell specification requires c-kit, notch signaling, and p27-mediated cell-cycle control. Dev Cell 2013;27:504515.

22 Huang SQ, Liao QJ, Wang XW, Xin DQ, Chen SX, Wu QJ, Ye G: Rnai-mediated knockdown of pituitary tumortransforming gene-1 (pttg1) suppresses the proliferation and invasive potential of pc3 human prostate cancer cells. Braz J Med Biol Res 2012;45:995-1001.

-23 Durocher Y, Chapdelaine A, Chevalier S: Tyrosine protein kinase activity of human hyperplastic prostate and carcinoma cell lines pc3 and du145. Cancer Res 1989;49:4818-4823.

24 Reynolds A, Leake D, Boese Q, Scaringe S, Marshall WS, Khvorova A: Rational sirna design for rna interference. Nat Biotechnol 2004;22:326-330.

25 Xiao X, Gaffar I, Guo P, Wiersch J, Fischbach S, Peirish L, Song Z, El-Gohary Y, Prasadan K, Shiota C, Gittes GK: M2 macrophages promote beta-cell proliferation by up-regulation of smad7. Proc Natl Acad Sci U S A 2014;111:E1211-1220.

-26 Paternot S, Bockstaele L, Bisteau X, Kooken H, Coulonval K, Roger PP: Rb inactivation in cell cycle and cancer: The puzzle of highly regulated activating phosphorylation of cdk4 versus constitutively active cdkactivating kinase. Cell Cycle 2010;9:689-699.

-27 Maddika S, Ande SR, Panigrahi S, Paranjothy T, Weglarczyk K, Zuse A, Eshraghi M, Manda KD, Wiechec E, Los M: Cell survival, cell death and cell cycle pathways are interconnected: Implications for cancer therapy. Drug Resist Updat 2007;10:13-29.

28 Coqueret 0: New roles for p21 and p27 cell-cycle inhibitors: A function for each cell compartment? Trends Cell Biol 2003;13:65-70.

29 Flores AN, McDermott N, Meunier A, Marignol L: Numb inhibition of notch signalling as a therapeutic target in prostate cancer. Nat Rev Urol 2014;11:499-507.

-30 Marignol L: Targeting notch in prostate cancer--combination is the key. Nat Rev Urol 2014;11:419.

-31 Bertrand FE, McCubrey JA, Angus CW, Nutter JM, Sigounas G: Notch and pten in prostate cancer. Advances in biological regulation 2014;56:51-65.

-32 Carvalho FL, Simons BW, Eberhart CG, Berman DM: Notch signaling in prostate cancer: A moving target. Prostate 2014;74:933-945.

-33 Alana L, Sese M, Canovas V, Punyal Y, Fernandez Y, Abasolo I, de Torres I, Ruiz C, Espinosa L, Bigas A, SR YC, Fernandez PL, Serras F, Corominas M, Thomson TM, Paciucci R: Prostate tumor overexpressed-1 (ptov1) down-regulates hes1 and hey1 notch targets genes and promotes prostate cancer progression. Mol Cancer 2014;13:74.

34 Marignol L, Rivera-Figueroa K, Lynch T, Hollywood D: Hypoxia, notch signalling, and prostate cancer. Nat Rev Urol 2013;10:405-413.

-35 Kashat M, Azzouz L, Sarkar SH, Kong D, Li Y, Sarkar FH: Inactivation of ar and notch-1 signaling by mir-34a attenuates prostate cancer aggressiveness. American journal of translational research 2012;4:432-442.

-36 Domingo-Domenech J, Vidal SJ, Rodriguez-Bravo V, Castillo-Martin M, Quinn SA, Rodriguez-Barrueco R, Bonal DM, Charytonowicz E, Gladoun N, de la Iglesia-Vicente J, Petrylak DP, Benson MC, Silva JM, CordonCardo C: Suppression of acquired docetaxel resistance in prostate cancer through depletion of notch- and hedgehog-dependent tumor-initiating cells. Cancer Cell 2012;22:373-388.

-37 Hahm ER, Chandra-Kuntal K, Desai D, Amin S, Singh SV: Notch activation is dispensable for d, l-sulforaphane-mediated inhibition of human prostate cancer cell migration. PLoS One 2012;7:e44957.

-38 Ye QF, Zhang YC, Peng XQ, Long Z, Ming YZ, He LY: Sirna-mediated silencing of notch-1 enhances docetaxel induced mitotic arrest and apoptosis in prostate cancer cells. Asian Pac J Cancer Prev 2012;13:2485-2489. 


\section{Cellular Physiology Cell Physiol Biochem 2015;36:1982-1990 \begin{tabular}{l|l} 
DOI: 10.1159/000430166 & $\begin{array}{l}\text { O 2015 S. Karger AG, Basel } \\
\text { www.karger.com/cpb }\end{array}$
\end{tabular} \\ Xue et al.: RBPJ in Prostate Cancer}

-39 Ye QF, Zhang YC, Peng XQ, Long Z, Ming YZ, He LY: Silencing notch-1 induces apoptosis and increases the chemosensitivity of prostate cancer cells to docetaxel through bcl-2 and bax. Oncology letters 2012;3:879884.

40 Danza G, Di Serio C, Rosati F, Lonetto G, Sturli N, Kacer D, Pennella A, Ventimiglia G, Barucci R, Piscazzi A, Prudovsky I, Landriscina M, Marchionni N, Tarantini F: Notch signaling modulates hypoxia-induced neuroendocrine differentiation of human prostate cancer cells. Mol Cancer Res 2012;10:230-238.

41 Kim SH, Sehrawat A, Sakao K, Hahm ER, Singh SV: Notch activation by phenethyl isothiocyanate attenuates its inhibitory effect on prostate cancer cell migration. PLoS One 2011;6:e26615.

-42 Wang Z, Li Y, Ahmad A, Banerjee S, Azmi AS, Kong D, Wojewoda C, Miele L, Sarkar FH: Down-regulation of notch-1 is associated with akt and foxm 1 in inducing cell growth inhibition and apoptosis in prostate cancer cells. J Cell Biochem 2011;112:78-88.

43 Wang Z, Li Y, Banerjee S, Kong D, Ahmad A, Nogueira V, Hay N, Sarkar FH: Down-regulation of notch-1 and jagged-1 inhibits prostate cancer cell growth, migration and invasion, and induces apoptosis via inactivation of akt, mtor, and nf-kappab signaling pathways. J Cell Biochem 2010;109:726-736.

44 Moreno CS: The sex-determining region y-box 4 and homeobox c6 transcriptional networks in prostate cancer progression: Crosstalk with the wnt, notch, and pi3k pathways. Am J Pathol 2010;176:518-527.

45 Mamaeva OA, Kim J, Feng G, McDonald JM: Calcium/calmodulin-dependent kinase ii regulates notch-1 signaling in prostate cancer cells. J Cell Biochem 2009;106:25-32.

46 Villaronga MA, Bevan CL, Belandia B: Notch signaling: A potential therapeutic target in prostate cancer. Curr Cancer Drug Targets 2008;8:566-580.

47 Leong KG, Gao WQ: The notch pathway in prostate development and cancer. Differentiation 2008;76:699716.

48 Scorey N, Fraser SP, Patel P, Pridgeon C, Dallman MJ, Djamgoz MB: Notch signalling and voltage-gated na+ channel activity in human prostate cancer cells: Independent modulation of in vitro motility. Prostate Cancer Prostatic Dis 2006;9:399-406.

49 Zayzafoon M, Abdulkadir SA, McDonald JM: Notch signaling and erk activation are important for the osteomimetic properties of prostate cancer bone metastatic cell lines. J Biol Chem 2004;279:3662-3670.

$\rightarrow 50$ Tilesi F, Fradiani P, Socci V, Willems D, Ascenzioni F: Design and validation of sirnas and shrnas. Curr Opin Mol Ther 2009;11:156-164.

51 Paddison PJ, Hannon GJ: Sirnas and shrnas: Skeleton keys to the human genome. Curr Opin Mol Ther 2003;5:217-224. 